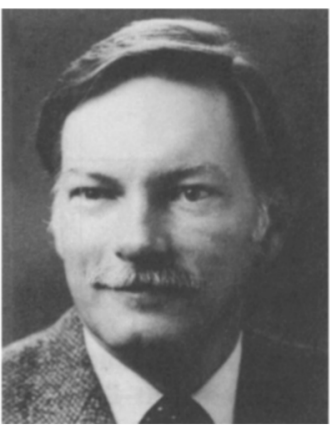

Gary McVay

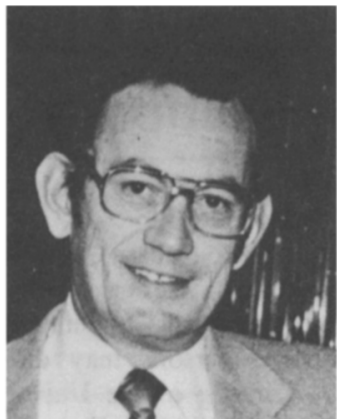

Paul Peercy

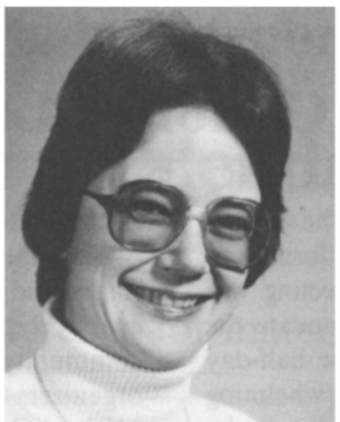

Julia Phillips

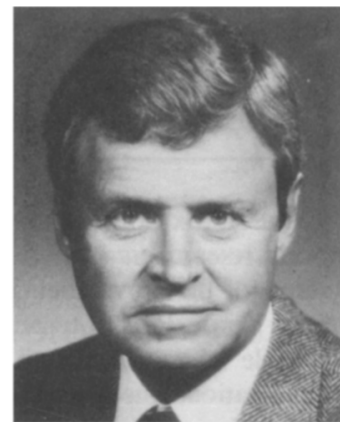

Dick Schwoebel

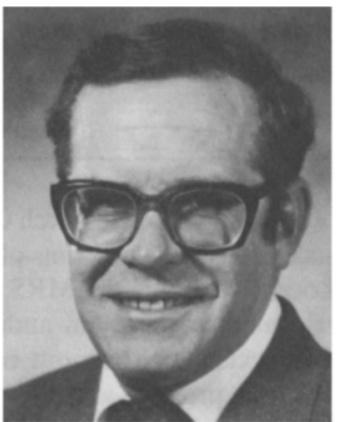

Woody White

\section{W. "Woody" White}

Chairman, Awards, Nominating, and Long-Range Planning Committees

As President of MRS in 1984, Woody White is no stranger to Society activities. He brings to these three key Committees his experience and ability to identify the talent and strengths of individual members and channel these qualities effectively to address the needs of the Society. The purpose of the Awards Committee is to recognize the achievements of both the young researcher and the established scientist to show both the appreciation of the Society and to serve as inspiration for the materials community as a whole. The Nominating Committee is responsible for pinpointing future leaders of the Society, and the Long-Range Planning Committee for generating innovative additions to Society activities. Collectively, the Committees work toward the identification and activation of talent and energies within the Society to spawn ideas that will materialize into benefits for the profession in the long term. Woody conducts research at the Solid State Division of the Oak Ridge National Laboratory.
Richard L. Schwoebel

Chairman, External Affairs Committee

The External Affairs Committee was instituted by the MRS Council at its meeting on December 1. It grew from a proposal of the Long-Range Planning Committee which recognized the Society's need to better define and fulfill its role on the national and international scene as a source of information and influence in materials research matters. The Committee will review requests for assistance from outside institutions and identify areas where the MRS should inject its expertise and make appropriate recommendations to the president. Dick has just completed terms as MRS Secretary and Councillor. $\mathrm{He}$ is a director of materials and process sciences at the Sandia National Laboratories in Albuquerque.

\title{
New Local MRS Groups Recognized at Plenary Session
}

Three new Student Chapters and two new Local Sections were recognized in a ceremony preceeding the Plenary Session at the Fall Meeting. After introduction by MRS President Woody White during the Monday evening event, Certificates of Charter were presented to representatives of the five local groups by President-Elect Elton Kaufmann. Kaufmann noted, "Charter presentation ceremonies for each new local group will occur twice: once at a major MRS national meeting where representatives of the entire materials community can observe, and once in the local venue for the benefit of those unable to attend the national meeting." He also pointed out, "Whereas, four of the five groups recognized this evening are indeed new, having been formed within the last five months, recognition of the $2 \frac{1}{1 / 2}$-year-old Student Chapter at UCLA is long overdue."

Kaufmann then proceeded to present UCLA's Certificate of Charter to Prof. Ray Orbach of the university's physics department. Orbach accepted the certificate on behalf of Chapter President Edward J. A. Pope and faculty advisor, Prof. Alfred S. Yue, who were unable to attend the meeting. The Student Chapter at the University of Pennsylvania was represented by student executive committee member Vicki Cajipe, who accepted the Certificate of Charter for the second MRS Student Chapter. Cajipe and several other University of Pennsylvania students and faculty advisor, Prof. John E. Fischer, arrived by car from Philadelphia just minutes before the ceremony began. (See Vol. IX, No. 5 for an article on the on-campus inauguration of this chapter.)

Kaufmann presented the Certificate of Charter for the third and most recent Student Chapter, Case Western Reserve University, to Joseph K. Doychak, a Student Award recipient this year, who represented his chapter and its faculty advisor, Prof. Terry E. Mitchell. (See the article elsewhere in this issue describing the on-campus ceremony for Case Western which took place one week later.)

Local Section recognition was headed by the North Carolina Section, the Society's first Local Section which was formed in the research triangle region of the state last June. Accepting the Certificate of Charter was Prof. Wei-Kan Chu of the University of North Carolina. (See the article in Vol. IX, No. 3 of the BULLETIN describing the inception of this new section.)

The final Local Section Charter presentation was made to the recently formed Northern California Section. Accepting the Charter on behalf of the group was Dr. Michael I. Current of the Xerox Palo Alto Research Center. (The inaugural meeting of this Section, arranged by Current and three others, is reported elsewhere in this issue.)

"Within the past month," Kaufmann concluded, "three additional universities and two local areas have expressed serious intentions of forming new MRS groups. So, members can expect to hear about many more of these inaugurations, and should certainly consider affiliating with or starting a local MRS group of their own."

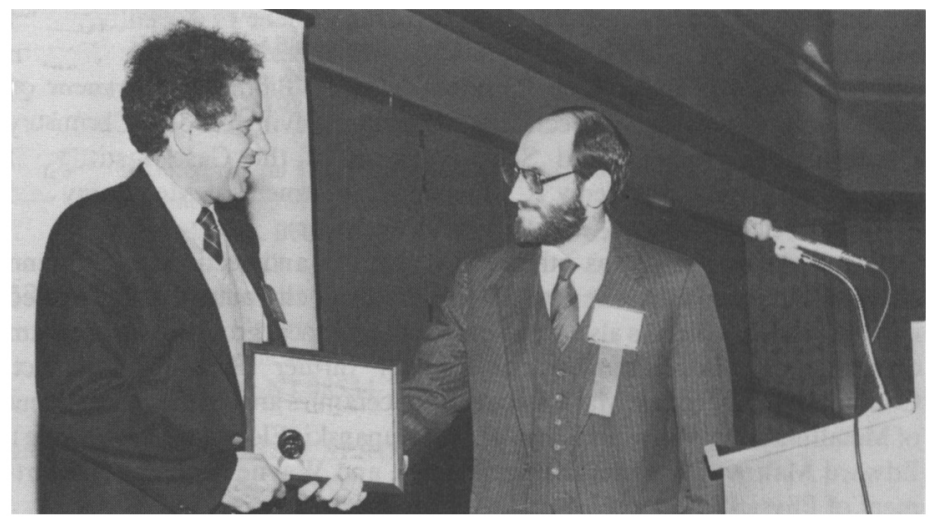

President-Elect Elton Kaufmann (right) presents Certificate of Charter to Ray Orbach, representing the 21/2-year-old UCLA Student Chapter. 